\title{
DAR A VER COM PALAVRAS: CINEMA E LITERATURA EM ITALO CALVINO
}

\author{
Bruna Fontes Ferraz \\ Universidade Federal de Minas Gerais \\ Maria Elisa Rodrigues Moreira \\ Universidade Federal de Minas Gerais
}

\begin{abstract}
Resumo: As discussões sobre as relações entre imagem e palavra são recorrentes na obra de Italo Calvino, que sempre buscou projetar em seus livros imagens que reconstruíssem seus mundos imaginários, pensando a página em branco como uma tela. Assim, mostraremos como a produção literária calviniana alia o imagético ao verbal, ora buscando construir imagens a partir das palavras, ora visando traduzir em palavras imagens mentais que antecediam suas narrativas, mas que ao mesmo tempo as influenciavam. Partindo, então, das intersecções entre imagem e palavra, chegaremos às considerações tecidas pelo próprio Calvino sobre o cinema e a literatura, apresentando um contexto no qual o cinema era o mundo para o escritor italiano e revelando os efeitos da Segunda Guerra Mundial tanto na visão que Calvino tinha das produções cinematográficas, quanto na inserção de um jovem escritor politicamente engajado no mundo da literatura. Diante dessas considerações, refletiremos sobre as relações entre literatura e cinema na obra do escritor, indicando de que modo a escrita calviniana pode ser considerada uma cinematografia de palavras.
\end{abstract}

Palavras-chave: Literatura. Cinema. Relações entre imagem e palavra. Italo Calvino.

As relações entre a literatura e o cinema ou, mais amplamente, entre a palavra e a imagem, são muitas, e traçam-se de maneiras diversas. Propomo-nos, aqui, a pensar em como essa relação se estabelece a partir da literatura e, em especial, a partir das reflexões que sobre ela traça o escritor Italo Calvino, que aponta a "visibilidade" como um dos valores literários que acredita mereça ser preservado neste milênio em que vivemos, articulando-as com suas reflexões sobre o cinema. Tomamos, pois, literatura e cinema sob o viés da primeira, no sentido que adotamos para o título deste texto: "dar a ver com palavras", fazer com que a imagem transpareça por meio destas, pensar a literatura como uma cinematografia de palavras, no que ela tem de projeção visual e plástica do verbal. 
Em sua proposta da "visibilidade", Calvino distingue dois tipos de processos imaginativos: aquele que partiria da palavra em direção à imagem e aquele que, partindo da imagem, chega à palavra. No primeiro caso, o escritor italiano ressalta a importância de se "ver com os olhos da imaginação" e "pensar por imagens", já que este seria um processo que ocorre frequentemente durante o ato de leitura, pois "conforme a maior ou menor eficácia do texto somos levados a ver a cena como se esta se desenrolasse diante de nossos olhos" (CALVINO, 1990, p. 99). A nossa mente funcionaria, para Calvino, como um "cinema mental", pois assim como no cinema, no qual a imagem do filme foi precedida por um texto escrito, "foi primeiro 'vista' mentalmente pelo diretor, em seguida reconstruída em sua corporeidade num set, para ser finalmente fixada em fotogramas de um filme" (CALVINO, 1990, p. 99), o nosso "cinema mental" - que funciona continuamente em nós - "não cessa nunca de projetar imagens em nossa tela interior" (CALVINO, 1990, p. 99).

A expressão verbal induz a criação de imagens na nossa imaginação, mas o processo contrário também foi evidenciado por Calvino ao afirmar que, em sua construção narrativa, partia muitas vezes de imagens para escrever seus textos. Nas suas palavras:

\begin{abstract}
A primeira coisa que me vem à mente na idealização de um conto é, pois, uma imagem que por uma razão qualquer apresenta-se a mim carregada de significado, mesmo que eu não o saiba formular em termos discursivos ou conceituais. A partir do momento em que a imagem adquire uma certa nitidez em minha mente, ponhome a desenvolvê-la numa história, ou melhor, são as próprias imagens que desenvolvem suas potencialidades implícitas, o conto que trazem dentro de si. Em torno de cada imagem escondem-se outras, forma-se um campo de analogias, simetrias e contraposições. (CALVINO, 1990, p. 104).
\end{abstract}

Nesse sentido, podemos aproximar a potencial imagem calviniana dos lampejos aos quais se refere Georges Didi-Huberman em seu Sobrevivência dos vaga-lumes: “Compreende-se, então, que uma experiência interior, por mais 'subjetiva', por mais 'obscura' que seja, pode aparecer como um lampejo para o outro, a partir do momento em que encontra a forma justa de sua construção, de sua narração, de sua transmissão" (DIDIHUBERMAN, 2011, p. 135). Conforme Didi-Huberman, ao fazer brilhar estes lampejos convertemo-nos em narradores, no sentido atribuído a esta palavra por Walter Benjamin, e fazemos dessa experiência visual uma narrativa que se tece nos interstícios entre a palavra e a imagem.

Se a afirmação de Didi-Huberman parte de imagens oníricas produzidas sob o regime do terror, o mundo imagético de Calvino parece derivar de um lugar oposto, tendo sido construído, segundo o próprio escritor, durante sua primeira infância, quando "a leitura das figurinhas sem palavras foi para [ele] sem dúvida uma escola de fabulação, de estilização, de 
composição da imagem" (CALVINO, 1990, p. 109). ${ }^{1}$ Num breve depoimento, o escritor italiano afirma que era costume da Itália redesenhar os comics americanos da época suprimindo os balões, de modo que cabia à criança inventar histórias a partir das imagens, ou seja, fazer-se narradora a partir desses fragmentos visuais postos à luz. A leitura das imagens das histórias em quadrinhos permitia que o menino Italo Calvino extraísse várias interpretações diferentes dos desenhos vistos, como ele relembra:

\begin{abstract}
Passava horas percorrendo os quadrinhos de cada série de um número a outro, contando para mim mesmo mentalmente as histórias cujas cenas interpretava cada vez de maneira diferente, inventando variantes, fundindo episódios isolados em uma história mais ampla, descobrindo, isolando e coordenando as constantes de cada série, contaminando uma série com outra, imaginando novas séries em que personagens secundários se tornavam protagonistas. (CALVINO, 1990, p. 109).
\end{abstract}

Desde muito jovem, pois, Calvino procurava unificar a "geração espontânea das imagens" à "intencionalidade do pensamento discursivo", buscava aliar a imagem à palavra, o visual ao verbal, mas sempre de forma potencial, de modo que, ao combinar e recombinar imagens e palavras, atingisse múltiplas possibilidades imaginativas. Tal operação foi mantida por Calvino mesmo na idade madura, como é o caso de sua obra $O$ castelo dos destinos cruzados, a qual elaborou por meio da extração de "histórias utilizando a sucessão das misteriosas figuras do tarô, interpretando a mesma figura cada vez de um modo diferente", num processo que "com certeza tem suas raízes naquele [seu] desvario infantil sobre as páginas repletas de figuras" (CALVINO, 1990, p. 110).

Partindo do mundo imagético, pois, Calvino chega ao "mundo do papel escrito", com o qual estabelece seus vínculos mais profundos e duradouros, afirmando que este "em algumas de suas margens é fronteiriço ao mundo do celuloide" (CALVINO, 2000, p. 56). Que margens seriam essas que tornariam, para o autor, tão próximos esses dois mundos, o mundo da imagem e o mundo da palavra, esses dois universos que podem ser representados pelo cinema e pela literatura?

\title{
Da palavra à imagem, da imagem à palavra
}

\footnotetext{
1 Não podemos nos esquecer, no entanto, que a experiência da militância partigiana de Calvino irá se juntar a esse manancial de formação de imagens, trazendo um pouco de "obscuridade" para o cenário resplandescente dos quadrinhos lidos na infầncia.
} 
A exploração da ligação entre palavra e imagem, no sentido em que a abordamos, não se apresenta como novidade, estando desde muito presente na narrativa, na filosofia, na poesia:

\begin{abstract}
A visualidade, enquanto ponto programático de uma poética, pode ser encontrada já nas manifestações de poesia não versificada que antecederam o movimento da poesia concreta. São conhecidos vários casos esparsos, ao longo da história, de experiências com a visualidade em suas mais diferentes formas, tanto na poesia brasileira quanto na mundial. (MENEZES, 1991, p. 12).
\end{abstract}

Sendo a poesia um dos campos nos quais o intercâmbio entre palavra e imagem é, ainda hoje, mais discutido, ela revelou-se o espaço por excelência da construção gramatical da imagem, lugar no qual se instalou a maior liberdade de troca entre elas, propiciando tantas e tão diversas experiências com a visualidade verbal. Teorizada e praticada pelos poetas, a poética da visualidade transitou entre os extremos, chegando a tocá-los.

Por um lado, temos a definição de imagem traçada por Octavio Paz, que assim a conceitua:

\begin{abstract}
Convém advertir, pois, que designamos com a palavra imagem toda forma verbal, frase ou conjunto de frases, que o poeta diz e que unidas compõem um poema. Estas expressões verbais foram classificadas pela retórica e se chamam comparações, símiles, metáforas, jogos de palavras, paronomásias, símbolos, alegorias, mitos, fábulas, etc. Quaisquer que sejam as diferenças que as separam, todas têm em comum a preservação da pluralidade de significados da palavra sem quebrar a unidade sintática da frase ou do conjunto de frases. (PAZ, 1976, p. 37-38).
\end{abstract}

No outro extremo, situa-se o trabalho da chamada "poesia visual", para buscarmos exemplos do contexto brasileiro, com um longo caminho intermediário preenchido pela poesia concreta. Conforme o poeta e ensaísta mexicano, a poesia é um espaço privilegiado da linguagem, no qual as palavras podem tornar-se imagens que dizem o indizível. É um "reino onde nomear é ser" (PAZ, 1976, p. 44), no qual "o poeta faz algo mais do que dizer a verdade; cria realidades que possuem uma verdade: a de sua própria existência" (PAZ, 1976, p. 45). A poesia seria, nesse sentido, um espaço essencialmente verbal, mas no qual a palavra pode assumir um caráter imagético capaz de expressar o inexpressável.

A poesia concreta, por seu turno, ainda que mantenha na palavra seu eixo principal, seu fundamento, trabalha a relação desta com a imagem de uma maneira diferente: é uma poesia estrutural, cujo aspecto visual é dado pela geometria das palavras, ou seja, uma poesia na qual a "matriz da visualidade adentra o poema como decorrência da organização do signo verbal no espaço" (MENEZES, 1991, p. 44). A partir dessa geometria, dessa arquitetura de letras e palavras, a poesia concreta chega aos limites da tradição verbal e aponta caminhos, 
passagens e interstícios para uma poética não verbal, uma "poesia visual", estritamente construída a partir de imagens visuais, fotográficas. Se, para uns, "a música da poesia é a música da linguagem; suas imagens são as visões suscitadas em nós pela palavra, não pela linha nem pela cor" (PAZ, 1976, p. 119), outros seguem a trilha oposta, abandonando por completo o verbal para dar lugar ao traçado, ao desenhado, ao colorido. Passa-se da "palavra que encarna" (PAZ, 1976, p. 98) à pura iconografia.

A filosofia apoia suas discussões em outro aspecto de percepção da relação entre palavra e imagem, tomando-a não como uma relação exteriorizada, mas como um processo interno à própria palavra. É nesse sentido que o filósofo e semioticista Charles S. Peirce, em seu estudo sobre os signos, elabora para estes uma classificação que os subdivide em nove categorias, conforme sua relação consigo mesmos, com seu referente ou com seu interpretante (PEIRCE, 1995). Interessa-nos, aqui, a segunda espécie de relações estabelecidas por Peirce, as que se dão entre o signo e o objeto representado, para a qual ele aponta as categorias do ícone, do índice e do símbolo, que podem tornar mais claro o sentido em que, neste artigo, utilizamos as expressões "imagem da palavra" e "dar a ver com palavras".

Segundo a teoria peirciana, o ícone é um signo que funciona como tal através de sua similaridade com o objeto representado, e pode ser subdividido em outras três categorias: imagem, diagrama e metáfora - a imagem significa por semelhança na aparência, como no caso das fotos; o diagrama tem por base a similaridade nas relações internas entre signo e objeto, no modo dos gráficos; já a metáfora estabelece um paralelo entre o significado do signo e algo que é diverso dele. O índice é um signo que representa algum evento, algum fato da experiência, algo externo a si: "Um índice é um signo que de repente perderia seu caráter que o torna um signo se seu objeto fosse removido [...]. Tal é, por exemplo, o caso de um molde com um buraco de bala como signo de um tiro, pois sem o tiro não teria havido buraco [...]” (PEIRCE, 1995, p. 74). Um símbolo, por sua vez, é um signo cujo caráter representativo reside na convencionalidade. Assim, “qualquer palavra comum, como 'dar', 'pássaro', ‘casamento', é exemplo de símbolo. O símbolo é aplicável a tudo o que possa concretizar a ideia ligada à palavra; em si mesmo, não identifica essas coisas [...], mas supõe que somos capazes de imaginar essas coisas, e a elas associar a palavra" (PEIRCE, 1995, p. 73).

Esses três "tipos" de signos estabelecem entre si um processo de encapsulamento, no qual o índice pressupõe o ícone, e o símbolo pressupõe o ícone e o índice. Desta afirmação podemos concluir o que nos interessa mais imediatamente: uma palavra - o símbolo por 
excelência - contém em si uma imagem - uma das espécies de ícone, conforme a classificação peirciana -, conclusão confirmada pelas palavras de Lúcia Santaella:

A afirmação de que a imagem é ícone já é relativamente enganadora; a de que a palavra é pura e simplesmente símbolo é decididamente equivocada. Os níveis de convencionalidade, que estão presentes, em maior ou menor medida, nas imagens, correspondem ao seu caráter simbólico, além de que há imagens alegóricas que figuram simbolicamente aquilo que denotam. Assim, também, há necessariamente imagem no símbolo, pois sem a imagem o símbolo não poderia significar. (SANTAELLA, 1992/1993, p. 44).

Nesse contexto, mesclando em suas obras o traçado e o colorido, a "palavra que encarna" e a iconografia, Calvino parece transitar com muita facilidade por entre imagens e palavras, indo de umas a outras para criar obras literárias. O escritor italiano está atento tanto às expressões e palavras que escolhe, observando o ritmo, o som e a imagem que evocam, quanto à arquitetura de sua obra, de modo que a moldura (cornice, em italiano) define a trama de muitos de seus livros, como As cidades invisíveis, O castelo dos destinos cruzados e Se um viajante numa noite de inverno.

Esse cuidado que tem o escritor italiano na escolha das palavras, no esmero com o estilo nos remete muito mais ao trabalho do poeta do que ao do prosador. A prosa calviniana seria, nesse sentido, tanto como um poema - imagético por natureza - quanto como um cinema - que funciona com a passagem sucessiva -, sobreposta em rapidez de imagens.

Assim, entendemos, juntamente com Paz, que as palavras aproximam-se da imagem sem perder seu lugar textual, narrativo, caminho por meio do qual procuraremos nos aproximar da literatura e do cinema conforme as pontuações de Italo Calvino. Ressaltamos ainda que para o escritor italiano, como ele evidencia ao falar do poema "Forse un mattino andando in un'aria di vetro" (Talvez certa manhã andando em ar de vidro), de Eugenio Montale, a poesia seria uma tela sobre a qual se projetam imagens, numa metáfora que só pode remeter ao cinema, esse "turbilhonar de imagens sobre uma tela branca" (CALVINO, 1993, p. 225).

Nessa perspectiva, trabalhando a escrita como uma espécie de processo de montagem cinematográfica a partir de movimentos próprios à palavra, a literatura cria um cenário no qual são possíveis os mais variados e imprevisíveis arranjos e efeitos, para que a cena literária se concretize numa constelação de imagens.

Nas palavras de Octavio Paz:

Ao imaginar o poema como uma configuração de signos sobre um espaço animado não penso na página do livro: penso nas Ilhas Açores vistas como um arquipélago de chamas numa noite de 1938, nas tendas negras dos nômades nos vales do 
Afeganistão, nos cogumelos dos paraquedas suspensos sobre uma cidade adormecida, na pequena cratera de formigas vermelhas em algum pátio citadino, na lua que se multiplica e se anula e desaparece e reaparece sobre o seio gotejante da Índia após as monções. Constelações: ideogramas. (PAZ, 1976, p. 110).

Nas letras de Italo Calvino:

\begin{abstract}
Seja como for, todas as "realidades" e as "fantasias" só podem tomar forma através da escrita, na qual exterioridade e interioridade, mundo e ego, experiência e fantasia aparecem compostos pela mesma matéria verbal; as visões polimorfas obtidas através dos olhos e da alma encontram-se contidas nas linhas uniformes de caracteres minúsculos ou maiúsculos, de pontos, vírgulas, de parênteses; páginas inteiras de sinais alinhados, encostados uns aos outros como grãos de areia, representando o espetáculo variegado do mundo numa superfície sempre igual e sempre diversa, como as dunas impelidas pelo vento do deserto. (CALVINO, 1990, p. 114).
\end{abstract}

O que ressalta desses dois trechos é que, diante de ambos, sentimo-nos na sala escura e confortável da lanterna mágica que desfila imagens, realidades, devaneios e delírios diante de nossos olhos. Mergulhamos, com os autores, num caleidoscópio cinemático onde letra e desenho se fundem numa mesma imagem indiferenciada, aproximamo-nos da margem em que os mundos do celuloide e da palavra se encontram.

\title{
A aventura de um espectador
}

Em “Autobiografia de um espectador", que compõe seu livro $O$ caminho de San Giovanni, ${ }^{2}$ o escritor italiano rememora sua adolescência para indicar seus vínculos com o cinema, afirmando que aqueles foram "anos em que o cinema era o mundo para [ele]" (2000, p. 41). O cinema, que frequentava então diariamente, ${ }^{3}$ apresentava-se como o único mundo possível num contexto de violência e guerra, como o único espaço em que era possível encontrar "a plenitude, a necessidade, a coerência" que se constituem como as "propriedades de um mundo" (CALVINO, 2000, p. 41). Continuando sua reflexão memorialística sobre o lugar que o cinema ocupava em sua vida nessa época, Calvino, que desobedecia às imposições dos pais para ver um filme, percebe que a sala escura projeta outras possibilidades de tempo e de espaço, de modo a contrastar "duas dimensões temporais diferentes, dentro e

2 O caminho de San Giovanni, publicado em italiano pela primeira vez em 1990, com organização de Esther Calvino, reúne textos memorialísticos e autobiográficos escritos por Calvino entre 1962 e 1977. Tais textos comporiam um projeto de livro que reuniria "exercícios de memória" e se intitularia Passagens obrigatórias (Passaggi obbligati). No entanto, como a obra ficou inacabada devido à morte prematura de Calvino, sua viúva renunciou ao título previsto por lhe parecer que muitas eram as passagens faltantes.

3 Ressalte-se que a época em que Calvino começou seu contato com o cinema (em meados dos anos de 1930) foi, justamente, um período em que o mundo passou por um boom imagético, uma vez que o cinema e a fotografia já se apresentavam, então, incorporados à sociedade. 
fora do filme" (CALVINO, 2000, p. 44). Durante o tempo vivido na sessão de cinema, Calvino se dá conta de que havia perdido duas horas no "mundo de fora", "sorvido numa suspensão do tempo, ou na duração de uma vida imaginária, ou no salto para trás nos séculos" (CALVINO, 2000, p. 44-45).

É interessante que relembremos, a partir da percepção calviniana das outras possibilidades de tempo e espaço instauradas pelo cinema, as noções de imagem-movimento e imagem-tempo propostas por Gilles Deleuze, ainda que para isso seja necessária uma breve digressão em nosso texto. Logo em seu prólogo ao livro Cinema 1: a imagem-movimento, Deleuze alerta para as mudanças importantes que o cinema trará às teorias da imagem, conforme abordadas por Peirce, uma vez que "o cinema impõe novos pontos de vista sobre este problema [o problema das imagens e dos signos]" (DELEUZE, 1985, p.7). Retomando as teses bergsonianas para, a partir delas, refletir sobre o cinema, Deleuze indica que o pensamento dos cineastas se constitui por meio desses dois tipos de imagem, e não por conceitos. Simplificadamente, podemos dizer que a imagem-movimento é a própria imagem oferecida pelo cinema, uma imagem em corte que traz, em si mesma, a ideia de movimento (um corte móvel, diz Deleuze, é o que o cinema alcança após seus primórdios, constituindo planos temporais, e não mais uma sequência de "instantes" ou "poses" privilegiados: a imagem-movimento representa um corte móvel da duração). Mas outro tipo de imagem surge a partir de uma contraposição ao predomínio da ação no cinema (situações sensório-motoras), levando ao centro da cena o espetáculo, o visivo que aparece como efeito ótico, como signo a ser observado (situações óticas e sonoras). Essa imagem-tempo decorre, pois, da imagemmovimento, e seu efeito temporal reside justamente na força da montagem (DELEUZE, 2005).

Se retomarmos o texto memorialístico de Italo Calvino, podemos perceber que o cinema por ele aclamado em sua juventude era o cinema americano clássico, a produção corrente de Hollywood pautada na ação, pois, embora os enredos fossem simples e convencionais, e os papéis dos personagens genéricos, o que interessava ao nosso espectador ainda iniciante era o "sabor de uma sociedade e de uma época". Assim, para ele, nos filmes americanos pairava "a mistificação do que aquela sociedade carregava por dentro", pois segundo Calvino: “[...] eu, espectador pertencente a outro sistema de mistificações, tinha algo para aprender quer daquele pouco de verdade, quer daquele muito de mistificação que os produtos de Hollywood me davam" (CALVINO, 2000, p. 48). 
Vale destacar, contudo, que não agrada a Calvino quando cinema e literatura se assemelham, conforme ele afirma em seu polêmico texto "Il realismo italiano nel cinema e nella narrativa" (O realismo italiano no cinema e na narrativa): "A mim incomoda o cinema quando se assemelha à literatura; e também a literatura quando se assemelha ao cinema" (CALVINO, 1995a, p. 1888). ${ }^{4}$ Ao contrário, o escritor parece preferir que um se aproxime do outro, que eles permutem elementos, mas sem tentar se fundir, mantendo assim suas características essenciais. Nesse sentido é possível compreender a preferência do escritor pelo cinema americano dos anos 1930 em relação ao cinema francês, o qual se assemelhava mais à literatura por seu caráter insinuante, pelos temas inquietantes e vagamente proibidos, considerando o regime ditatorial vigente:

Diferentemente do cinema francês, o cinema americano de então não tinha nada a ver com a literatura: talvez esse seja o motivo pelo qual ele se destaca em minha experiência com um relevo isolado do resto: estas minhas memórias de espectador pertencem às memórias de antes que a literatura me chegasse. (CALVINO, 2000, p. 49).

Embora não fosse aquele cinema que mais se aproximava da literatura o que agradava ao jovem Calvino, podemos perceber que a paixão pelo cinema nutrida pelo escritor durante a adolescência contribuiu para a sua formação literária, possibilitando a ele tanto distinguir os níveis de realidade presentes nas produções cinematográficas americanas, como identificar e discernir o verdadeiro do falso. O cinema, propício aos devaneios, permitiu que o espectador se tornasse um escritor com forte veia imagética, capaz de transformar suas narrativas num grande quebra-cabeça também visual.

No entanto, esse cinema - "fábrica de sonhos", como nos diria Jean-Luc Godard capaz de nos projetar para outros mundos foi tolhido pelo fascismo, sendo que a realidade da guerra provocou uma nova modalidade de fruição dos filmes. A violência da guerra impôs ao cinema italiano um realismo exacerbado, uma crueza de imagens, de modo a revelar ao espectador o mundo ao qual ele pertencia - com o neorrealismo italiano podemos perceber as primeiras manifestações do cinema moderno que surge no entre guerras, e a afirmação daquele tipo de cinema que, conforme Deleuze (2005), ao explicitar seu caráter visivo, faz com que as distinções entre espectador e espetáculo deixem de ser tão nítidas, uma vez que tanto os espectadores quanto os personagens passam a fundar sua experiência na percepção de situações óticas e sonoras. O fascínio cinematográfico se reduz para Calvino, assim, ao

4 "A me il cinema quando somiglia alla letteratura dà fastidio; e la letteratura quando somiglia al cinema anche". É interessante destacar, ainda, que é justamente ao realismo italiano que Deleuze recorre para tratar do cinema pensado mais pelo viés da imagem-tempo que da imagem-movimento. 
cinema americano da década de 1930, pois, após a Segunda Guerra Mundial, nem os filmes nem ele continuariam os mesmos. Sobre esse fato, o escritor testemunha:

Do pós-guerra em diante o cinema foi visto, discutido, feito, de maneira totalmente distinta. Não sei quanto o cinema italiano do pós-guerra mudou nosso modo de ver o mundo, mas certamente mudou nosso modo de ver o cinema (qualquer cinema, mesmo o americano). Não há um mundo dentro da tela iluminada na sala escura e lá fora outro mundo heterogêneo e separado por uma nítida descontinuidade, oceano ou abismo. A sala escura desaparece, a tela é uma lente de aumento pousada sobre o exterior cotidiano, e nos obriga a fitar aquilo pelo qual o olho nu tende a deslizar sem se deter. (CALVINO, 2000, p. 56).

Calvino reforça tal concepção no texto que anteriormente citamos, "Il realismo italiano nel cinema e nella narrativa", no qual expõe a sua preferência pelo cinema de teor onírico, aventuresco, fantástico em relação ao neorrealismo italiano. O escritor ainda ressalta que o cinema do pós-guerra se associou à literatura contemporânea e que, embora tal aliança seja uma coisa boa, para ele

ver os filmes perdeu muito do seu caráter maravilhoso, já que aqueles que os fazem são alguns de nossos amigos: o filme não é mais aquela estranha flor de uma planta artificial e contaminada, com raízes que sobem pelo circo equestre, pelo castelo dos mistérios, pelos cartões de bromo, pelos tabuleiros de jogral. (CALVINO, 1995a, p. 1889, tradução nossa). ${ }^{5}$

Depreendemos dessa afirmação que o cinema pode ser, para o nosso escritor, um campo de abertura a novas possibilidades, que reflita não somente sobre movimentos intelectuais, mas que, em certa medida, responda às exigências e gostos do público. É nesse sentido que Calvino considera que o cinema americano do anteguerra respondia a uma necessidade de distância, ${ }^{6}$ "de dilatação dos limites do real", de modo a evidenciar “dimensões incomensuráveis, abstratas como entidades geométricas, mas também concretas, absolutamente repletas de caras e situações e ambientes que, com o mundo da experiência direta, estabeleciam uma rede própria (e abstrata) de relações" (CALVINO, 2000, p. 56). Com a guerra, o cinema se fixa no "sentimento irreversível de que tudo está perto, apertado, em cima da gente" (CALVINO, 2000, p. 58), de modo que o mundo de fora, em lugar de apresentar determinadas coisas da vida, oprime e reduz a lente cinematográfica a uma realidade que se impõe a nós.

\footnotetext{
5 "[...] vedere i film ha perso molto del suo carattere meraviglioso, adesso che quelli che li fanno sono dei nostri amici: il film non è più quello strano fiore d'una pianta spuria e contaminata, con radici che vengono su dal circo equestre, dal castello dei misteri, dalle cartoline al bromo, dai tabelloni del cantastorie".

6 Vale destacar, contudo, que se Calvino parece preferir o cinema clássico americano, ele termina seu texto "Autobiografia de um espectador" com uma bonita homenagem ao cinema de Fellini, tecendo praticamente um breve ensaio sobre esse cineasta, no qual afirma poder ser encontrado esse cinema de distância, ainda que Fellini seja um diretor essencialmente moderno, em contraposição ao grande cinema hollywoodiano dos anos de 1930 e 1940.
} 
A relação entre a arte e o mundo exterior deve, assim, ser mediada pelas várias possibilidades de expressão dessa realidade quando transpostas para o ambiente artístico, mais especificamente, no caso que aqui abordamos, para o ambiente cinematográfico. Tal perspectiva foi apontada por Walter Benjamin que, ao citar Werfel, observa que:

[...] é a tendência estéril de copiar o mundo exterior, com suas ruas, interiores, estações, restaurantes, automóveis e praças, que têm impedido o cinema de incorporar-se ao domínio da arte. "O cinema ainda não compreendeu seu verdadeiro sentido, suas verdadeiras possibilidades... Seu sentido está na sua faculdade característica de exprimir, por meios naturais e com uma incomparável força de persuasão, a dimensão do fantástico, do miraculoso e do sobrenatural." (BENJAMIN, 1994, p. 177).

Como vimos, também Calvino já percebia a natureza potencial presente no cinema ao aliar "realidade" e "fantasia", procedimento utilizado pelo cinema americano do anteguerra. No entanto, o escritor italiano já se referia também à possibilidade de o cinema, assim como outros mass media, contribuírem para inundar a humanidade com um "dilúvio de imagens pré-fabricadas", como anunciou em sua conferência acerca da "Visibilidade":

Hoje somos bombardeados por uma tal quantidade de imagens a ponto de não podermos distinguir mais a experiência direta daquilo que vimos há poucos segundos na televisão. Em nossa memória se depositam, por estratos sucessivos, mil estilhaços de imagens, semelhantes a um depósito de lixo, onde é cada vez menos provável que uma delas adquira relevo. (CALVINO, 1990, p. 107).

Calvino escreve sobre a visibilidade e sobre o acúmulo de imagens prontas, isto é, imagens que não suscitam nenhuma reflexão, durante a década de 1980, num contexto em que as experiências pessoais passavam a ser substituídas pelas imagens televisivas, fato que adquiriu relevância ainda no início da segunda metade do século XX, quando as novas mídias começaram a produzir uma crescente massificação e banalização das imagens. A vida das sociedades se anunciava, assim, como uma imensa acumulação de espetáculos, tal como afirmou Guy Debord (1997) - que cunhou o termo "sociedade do espetáculo", considerando que a sociedade passou, desde então, a se pautar pelas aparências, de modo a negar o visível da vida ao transformar as imagens em puros artifícios. A sociedade espetacularizada seria, portanto, visível demais, e a imensa claridade das luzes artificiais geraria um ofuscamento.

Nesse sentido, podemos lembrar novamente Didi-Hubermann em Sobrevivência dos vagalumes ao distinguir a "luce" dos "lucciole", ou seja, a "grande luz" dos "vagalumes", pois numa sociedade ofuscada pela "luce", cabe aos "lucciole" resistirem e sobreviverem. É esse papel de vagalume que cumpriria, para Calvino, a literatura, a única instância capaz de sobreviver à espetacularização social. Por isso, o escritor italiano propõe uma "pedagogia da 
imaginação", "que nos habitue a controlar a própria visão interior sem sufocá-la e sem, por outro lado, deixá-la cair num confuso e passageiro fantasiar, mas permitindo que as imagens se cristalizem numa forma bem definida, memorável, auto-suficiente, “icástica"” (CALVINO, 1990, p. 108).

\section{Palavras na tela, projeções imagéticas}

As reflexões de Italo Calvino sobre a imagem, tecidas com os fios da literatura e do cinema, fazem descortinar-se diante de nós, como projetadas sobre a tela do cinema, palavras que colocam em movimento imagens múltiplas, articuladas pela "câmera que permite o registro" e pela "moviola que permite a montagem" desse cinema mental que a literatura pode propiciar. $\mathrm{Na}$ folha/tela em branco, o escritor projeta, por meio de suas palavras, as imagens que se apresentam a ele no início do processo de escrita: ao começar a "pôr o preto no branco" (CALVINO, 1990, p. 105), Italo Calvino afirma que precisa traduzir em palavras estas imagens "carregadas de significado" que passarão então a seguir o fio da narrativa literária.

O "mundo do papel escrito" e o "mundo do celuloide" se encontram então nessa fronteira que os avizinha e permite que se leia ou se assista a uma cinematografia de palavras, nessa margem que garante que o "pensar por imagens" não vá morrer diante de um universo de multiplicação descontrolada das mesmas, desde que se mantenha "a capacidade de pôr em foco visões de olhos fechados, de fazer brotar cores e formas de um alinhamento de caracteres alfabéticos negros sobre uma página branca" (CALVINO, 1990, p. 107-108).

Ao abrir as cortinas desse cinema, as palavras dão a ver imagens que apenas à literatura é permitido apresentar: afinal, “aqui nesta página é preciso encontrar espaço para tudo, a estrada principal cheia de poeira, o rio, a ponte, lá está Agilulfo, que passa com seu cavalo de cascos ligeiros, toc-toc, toc-toc, pesa pouco aquele cavaleiro sem corpo, o cavalo pode fazer milhas e milhas sem se cansar" (CALVINO, 1995b, p. 83), nos diz a freiranarradora de $O$ cavaleiro inexistente. Com ela continuamos a seguir os trajetos desses personagens, "uma linha reta, às vezes interrompida por ângulos", que representa o percurso de Agilulfo, o cavaleiro, ou "outra linha cheia de garatujas e vaivens", por meio da qual podemos vislumbrar os passos de Gurdulu, espécie de escudeiro fiel (CALVINO, 1995b, p. $83-84)$. 
Com Irmã Teodora encerramos esse breve percurso pela palavra-imagem calviniana, deixando antever um pouco mais de sua cinematografia literária:

\begin{abstract}
Mas como prosseguir com a história, se me ponho a trilhar assim a página branca, escavando dentro vales e depressões, fazendo percorrerem-na enrugações e arranhaduras, lendo nelas as cavalgadas dos paladinos? Melhor seria, para ajudar-me a narrar, se me desenhasse um mapa dos lugares, com a suave terra da França, e a orgulhosa Bretanha, e o canal da Inglaterra cheio de vagalhões negros, e lá em cima a alta Escócia, e aqui embaixo os ásperos Pireneus, e a Espanha ainda em mãos infiéis, e a África mãe de serpentes. Depois, com flechas e com cruzinhas e com números poderia assinalar o caminho deste ou daquele herói. (CALVINO, 1995b, p. 101).
\end{abstract}

\title{
Referências
}

BENJAMIN, Walter. A obra de arte na era de sua reprodutibilidade técnica. In: BENJAMIN, Walter. Magia e técnica, arte e política: ensaios sobre literatura e história da cultura. Tradução de Sérgio Paulo Rouanet. São Paulo: Brasiliense, 1994.

CALVINO, Italo. Seis propostas para o próximo milênio. Tradução de Ivo Barroso. 2. ed. São Paulo: Companhia das Letras, 1990.

Eugenio Montale, "Forse un mattino andando". In: CALVINO, Italo. Por que ler os clássicos. Tradução de Nilson Moulin. São Paulo: Companhia das Letras, 1993. p. 216-226.

Il realismo italiano nel cinema e nella narrativa. In: . Saggi. Milano: Mondadori, 1995a. v.2. p. 1888-1890.

. O cavaleiro inexistente. Tradução de Nilson Moulin. São Paulo: Companhia das Letras, $1995 \mathrm{~b}$.

Autobiografia de um espectador. In: CALVINO, Italo. O caminho de San Giovanni. Tradução de Roberta Barni. São Paulo: Companhia das Letras, 2000. p. 39-64.

DEBORD, Guy. A sociedade do espetáculo. Tradução de Estela dos Santos Abreu. Rio de Janeiro: Contraponto, 1997.

DELEUZE, Gilles. Cinema 1: a imagem-movimento. Tradução de Stella Senra. São Paulo: Brasiliense, 1985.

$\overline{\text { Brasiliense, } 2005 .}$

Cinema 2: a imagem-tempo. Tradução de Eloisa de Araújo Ribeiro. São Paulo:

DIDI-HUBERMAN, Georges. Sobrevivência dos vaga-lumes. Tradução de Vera Casa Nova e Márcia Arbex. Belo Horizonte: Ed. UFMG, 2011.

MENEZES, Philadelpho. Poética e visualidade: uma trajetória da poesia brasileira contemporânea. Campinas: Ed. UNICAMP, 1991.

PAZ, Octavio. Signos em rotação. Tradução de Sebastião Uchoa Leite. 2. ed. São Paulo: Perspectiva, 1976.

PEIRCE, Charles Sanders. Semiótica. Tradução de José Teixeira Coelho Neto. 2. ed. São Paulo: Perspectiva, 1995.

SANTAELLA, Lúcia. Palavra, imagem e enigmas. Revista USP, São Paulo, n.16, p. 37-51, dez./fev. 1992/1993. 
[Recebido em março de 2012 e aceito para publicação em junho de 2012]

\title{
Giving to see with words: Cinema and Literature in Italo Calvino
}

\begin{abstract}
Discussions about the relations between Image and Word are recurring in the work of Italo Calvino, who had always searched to project in his books images that might rebuild his imaginary worlds, in order to think the blank page such as a movie screen. So, we'll demonstrate how the Calvino's literary produce combines the imaging to the verbal, searching to build images from the word, or aiming to translate mental images into words. Starting, so, the intersections between image and word, we'll get the considerations made by Calvino about cinema and literature, presenting a context in which the cinema was the world to the Italian writer and revealing the effects of World War II such Calvino's vision of the cinematography production, as the insertion of a politically engaged young writer in the literature's world. In this paper, we aim to reflect about the relations between literature and cinema in Calvino's work, remarking how the whole calvinian writing can be considered as a cinematography of words.
\end{abstract}

Keywords: Literature. Cinema. Relations between Image and Word. Italo Calvino. 